\title{
Linezolid induced thrombocytopenia
}

\author{
P. Muthamil*, R. Mani
}

Department of Pharmacology, Coimbatore Medical College, Coimbatore, Tamil Nadu, India

\author{
Received: 02 March 2020 \\ Revised: 05 May 2020 \\ Accepted: 07 May 2020 \\ *Correspondence: \\ Dr. P. Muthamil, \\ Email: muthamilperiyasamy@gmail.com
}

Copyright: (c) the author(s), publisher and licensee Medip Academy. This is an open-access article distributed under the terms of the Creative Commons Attribution Non-Commercial License, which permits unrestricted non-commercial use, distribution, and reproduction in any medium, provided the original work is properly cited.

\begin{abstract}
Linezolid, an oxazolidinone antibiotic active against gram-positive bacteria is used in the treatment of vancomycin resistant Enterococci and MRSA. It is generally tolerated except for the $32 \%$ chance of thrombocytopenia on long term usage of linezolid. A 25-year-old male after renal transplantation was administered linezolid for antibiotic prophylaxis. His platelet count dropped from 1,68,000 cells to 74,000 on day 2. The platelet counts further dropped to 58,000 on day 3 , followed which linezolid was withdrawn. His platelet improved to 88,000 on day 5 following withdrawal of linezolid. Though we are vigilant about thrombocytopenia on long term usage of linezolid, here we report a rare case of linezolid induced thrombocytopenia within 2 days of starting the antibiotic. This necessitates the increased vigilance on linezolid usage. Platelet count needs to be monitored as early as the start of treatment with linezolid.
\end{abstract}

Keywords: Linezolid, Methicillin resistant Staphylococcus aureus, Thrombocytopenia, Vancomycin, Vigilance

\section{INTRODUCTION}

Linezolid, an oxazolidinone antibiotic active against gram-positive bacteria is used in the treatment of vancomycin resistant Enterococci, methicillin resistant staphylococcus aureus (MRSA). It is generally tolerated except for the $32 \%$ chance of thrombocytopenia on long term usage of linezolid.

Thrombocytopenia occurs after long term exposure to linezolid usually after 10 days. Drug label bears the warning that platelet count needs to be monitored when administered along with drugs which reduces the platelet count and in patients with increased risk of bleeding. ${ }^{1}$

\section{CASE REPORT}

A 25 years old male after renal transplantation who was already on anti-graft rejection medications steroids, mycophenolate mofetil and tacrolimus along with other intensive care therapy. Linezolid was started as antibiotic prophylaxis on post-operative day 1 .

Platelet count was monitored twice daily. Following the introduction of linezolid prophylaxis, his platelet count dropped from $1,68,000$ cells to 74,000 on day 2 . The platelet counts further dropped to 58,000 on day 3 , followed which linezolid withdrawn. His platelet improved to 88,000 on day 5 following withdrawal of linezolid (Table 1). Hence this case was received as an adverse drug reaction to pharmacovigilance monitoring centre, department of pharmacology, Coimbatore Medical College, Coimbatore, Tamil Nadu, India.

\section{DISCUSSION}

Vancomycin resistant gram-positive bacteria are increasing in number. Linezolid, an oxazolidinone antibiotic used in the prophylaxis and in the treatment of vancomycin resistant enterococci and MRSA infections. ${ }^{1}$ Adverse effects like diarrhoea, nausea, head ache are 
common. Serious adverse effect of linezolid is thrombocytopenia. ${ }^{2}$ Linezolid induced thrombocytopenia occurs after 10 days of treatment with linezolid. ${ }^{1-3}$ The mechanism of causing thrombocytopenia is by formation of quinine like antibodies against platelets immediately after linezolid (Figure 2). ${ }^{4}$ With mycophenolate mofetil and tacrolimus thrombocytopenia is uncommon. Here is a report of first case of linezolid induced thrombocytopenia on the day 2 after the start of treatment with linezolid in this study Coimbatore Medical College Hospital. On linezolid withdrawal platelet count improved from 58,000 on day 3 to 88,000 on day 5 . This implies the early monitoring of platelet count from the day 2 onwards.

Table 1: Platelet count.

\begin{tabular}{|llllll|}
\hline Post-operative day & Day 1 & Day 2 & Day 3 & Day 4 & Day 5 \\
\hline Platelet count 8 am & $1,68,000$ & 74,000 & 58,000 & 60,000 & 88,000 \\
\hline Platelet count 8 pm & 90,000 & 60,000 & 58,500 & 68,000 & 88,650 \\
\hline
\end{tabular}

Time from initiation of linezolid therapy to development of thrombocytopenia

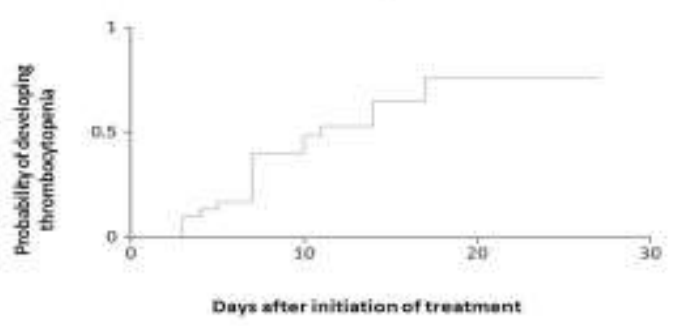

Figure 1: Usual presentation of thrombocytopeniaafter 3 days. ${ }^{5}$

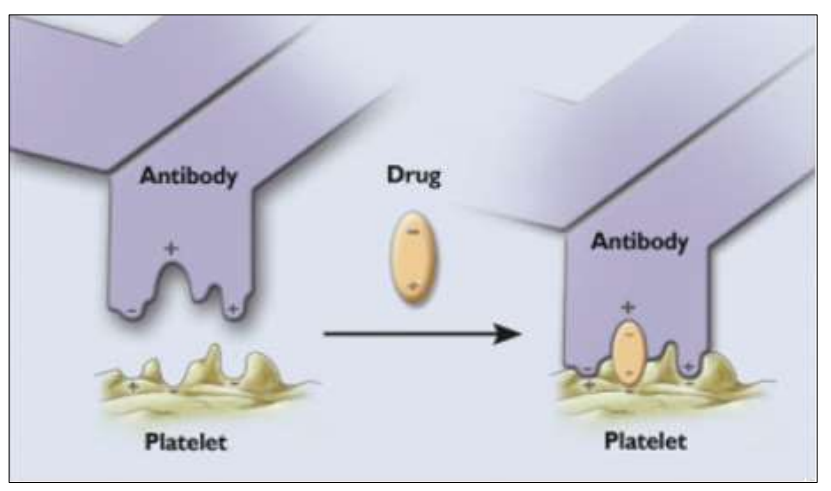

Figure 2: Mechanism of linezolid induced thrombocytopenia. ${ }^{6}$

\section{CONCLUSION}

Though we are vigilant about thrombocytopenia on long term usage of linezolid, here is a report of rare case of linezolid induced thrombocytopenia within 2 days of starting the antibiotic. This necessitates the increased vigilance on linezolid usage. This case scenario alarms increased surveillance on platelet count on linezolid usage.

Funding: No funding sources

Conflict of interest: None declared

Ethical approval: Not required

\section{REFERENCES}

1. Attassi K, Hershberger E, Alam R, Zervos MJ. Thrombocytopenia associated with linezolid therapy. Clin Infect Dis. 2002;34(5):695-8.

2. The mechanism for linezolid (Zyvox) induced thrombocytopenia. Available at: https://www.ebmconsult.com/articles/how-doeslinezolid-cause-thrombocytopenia. Accessed on 12 February 2020.

3. Akl A. Hematological abnormalities post renal transplantation. Int Urol Nephrol. 2010;42(1):151-64.

4. Natsumoto B, Yokota K, Omata F, Furukawa K. Risk factors for linezolid-associated thrombocytopenia in adult patients. Infect. 2014;42(6):1007-1.

5. Nukui Y, Hatakeyama S, Okamoto K, Yamamoto T, Hisaka A, Suzuki H, et al. High plasma linezolid concentration and impaired renal function affect development of linezolid-induced thrombocytopenia. J Antimicrob Chemother. 2013;68(9):2128-33.

6. Loo AS, Gerzenshtein L, Ison MG. Antimicrobial drug-induced thrombocytopenia: a review of the literature. Semin Thromb Hemost. 2012;38(8):81829.

Cite this article as: Muthamil $\mathrm{P}$, Mani R. Linezolid induced thrombocytopenia. Int J Basic Clin Pharmacol 2020;9:1130-1. 